\title{
Effect of Electron Beam Method on Processing of Titanium Technogenic Material
}

\author{
Katia Vutova ${ }^{1, *}$, Vania Vassileva ${ }^{1}$, Vladislava Stefanova ${ }^{2}$, Dinesh Amalnerkar ${ }^{3}$ and \\ Takeshi Tanaka 4 \\ 1 Institute of Electronics, Bulgarian Academy of Sciences, Sofia 1784, Bulgaria; vvvania@abv.bg \\ 2 Department of metallurgy of non ferrous metals and semiconductors technologies, University of Chemical \\ Technology and Metallurgy, Sofia 1756, Bulgaria; vps@uctm.edu \\ 3 Institute of Nano Science and Technology, Hanyang University, Seoul 04763, South Korea; \\ dpa54@yahoo.co.in \\ 4 Hiroshima Institute of Technology, Hiroshima 731-5193, Japan; tanaka@cc.it-hiroshima.ac.jp \\ * Correspondence: katia@van-computers.com; Tel.: +359-2-979-5900
}

Received: 6 May 2019; Accepted: 12 June 2019; Published: 14 June 2019

\begin{abstract}
This study reveals the efficiency of the electron beam processing of titanium technogenic material with a high level of impurities and the quality of the obtained metal in correlation to process parameters which are discussed. The influence of the beam power and melting time on the composition variation, morphologies, hardness of metal samples and mass losses is investigated. Based on the different technological parameters, the removal efficiency of impurities is also discussed, and the corresponding experiments are carried out in order to make a comparison. Different thermal process conditions are realized during the single-melt operation. Chemical and metallographic analyses are performed, and the results are discussed. The hardness of the titanium decreases by prolonging the time of the electron beam processing. A maximal overall removal efficiency of $99.975 \%$ is seen at $5.5 \mathrm{~kW}$ beam power for a 40 min melting time and the best purification of $\mathrm{Ti}(99.996 \%)$ is achieved.
\end{abstract}

Keywords: titanium technogenic material; electron beam; melting process; removal efficiency

\section{Introduction}

Titanium and titanium alloys are widely used in aerospace, chemical, bio-medical and other industries due to their weight saving (light in weight), heat resistance, resistance to embrittlement at low temperatures, high corrosion resistance, high tensile strength, low-thermal expansion, and toughness, and with these advantages they have been key materials in high-tech areas [1-7]. They are commonly produced by traditional vacuum arc remelting [8]. However, this process suffers from common problems, such as inhomogeneity of composition and structure, lower material quality, and possible retention of high-density and low-density inclusions in the metal ingot [9]. Electron beam melting technology exhibits extensive application prospects for undesired impurities removal, for solving the problem of inhomogeneity of ingot structure and composition at melting various materials, and also for breaking the length limitation of vacuum arc remelting ingots [10-23]. The microstructure of the obtained ingots after processing is important due to its influence on the mechanical properties. Furthermore, a wider range of initial materials, including technogenic materials, can be used in the electron beam method, while a compacted electrode must be fabricated in vacuum arc remelting. The tremendous kinetic energy of electrons is transformed into heat energy for melting the material after the impact of the beam with the surface of the treated material. In the furnaces, a combination of a high vacuum environment and material superheating (up to 1.3-1.5 of the melting temperature), results in a highly efficient refining process. The electron beam method (EBM) is an effective method that has been utilized for refining refractory 
metals [24-27] and alloys [28,29], purifying solar-grade silicon [30,31], obtaining superalloys [18,32,33], high-purity special steels, and so on. We note that the electron beam melting method mentioned in this investigation involves a melting furnace that produces ingots by using an electron beam, which differs from the common adoption for the additive manufacturing method.

The purpose of this study is to examine the effects of the electron beam method on processing titanium technogenic material. The influences of melting power and the refining time on the removal efficiency, composition, the metal microstructure, hardness and material losses are studied in order to increase the efficiency of the EBM, i.e., to improve the composition and quality of the produced metal ingots in the processing of the investigated Ti technogenic material.

\section{Materials and Methods}

The experiments for electron beam processing of titanium technogenic material were conducted using $60 \mathrm{~kW}$ electron beam furnace ELIT 60 (Leybold GmbH, Cologne, Germany, Institute of electronics at the Bulgarian Academy of Sciences, Sofia, Bulgaria) in the laboratory for physical problems of electron beam technologies. The experimental furnace consisted of one electron gun with an accelerating voltage of $24 \mathrm{kV}$, a melting chamber with a volume of around a cubic meter and with two observation windows, a water-cooled crucible, a circulation water cooling system, and two independent vacuum systems. The melting chamber was evacuated to a pressure of $2 \times 10^{-2} \mathrm{~Pa}$ and the electron gun chamber was evacuated to a pressure of 3-6 $\times 10^{-3} \mathrm{~Pa}$. After pre-processing, the raw material was placed in the water-cooled crucible and then the metal was irradiated and heated by an electron beam with a beam spot radius of $10 \mathrm{~mm}$ (Figure 1). A copper cylindrical crucible used was with a height of $60 \mathrm{~mm}$ and diameter of $50 \mathrm{~mm}$.

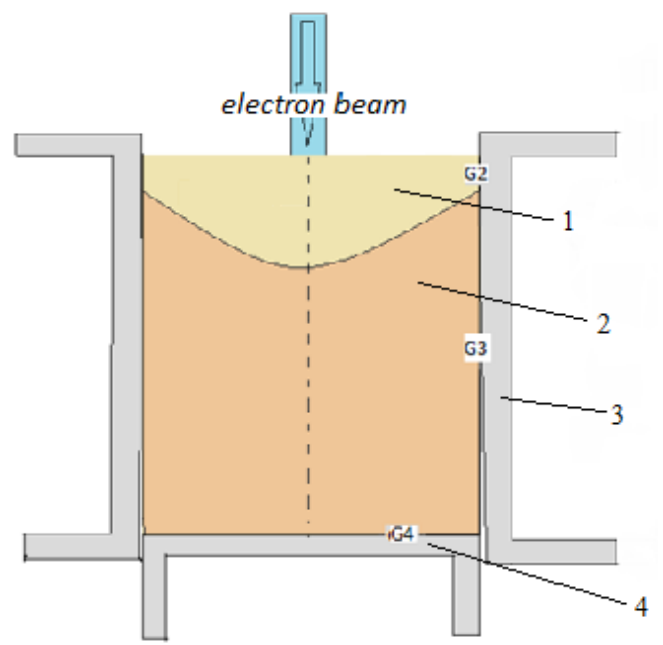

Figure 1. Diagram of the electron beam melting (EBM) process: (1) liquid metal pool; (2) solidifying ingot; (3) water-cooled side wall of the crucible; (4) water-cooled bottom.

The investigated technogenic material (titanium gratings scrap) contained $84.01 \%$ Ti and $\mathrm{Ir}, \mathrm{Fe}, \mathrm{Al}$, $\mathrm{Si}$, and $\mathrm{Cu}$ with high concentrations (more than $1 \%$ ). The other controlled impurities in this study were tungsten, tantalum, and cadmium. In accordance with the requirements, the obtained refined Ti should contain overall impurities of less than 1\% (Ti 99\%) and the content of iridium and iron should be reduced to a minimum. An investigation under different melting parameters (melting power and refining time) was performed, taking into account the kinetic and thermodynamical limitations depending on the material. The raw materials mass was in the range of $100 \mathrm{~g}$ to $150 \mathrm{~g}$.

Experiments were performed with different electron beam powers (with different temperatures) and refining times to examine the effects of melting process parameters on the removal efficiency, material losses, hardness and microstructures of ingots. The raw (initial) material was melted under 
single processing at melting powers of $2.5 \mathrm{~kW}\left(T=1697^{\circ} \mathrm{C}\right), 3.5 \mathrm{~kW}\left(T=1777{ }^{\circ} \mathrm{C}\right)$ and $5.5 \mathrm{~kW}$ $\left(T=1877^{\circ} \mathrm{C}\right.$ ) for different lengths of melting time-15 $\mathrm{min}, 25 \mathrm{~min}$ and $40 \mathrm{~min}$.

A stereo and a light microscope allow a study of the topography of the macro or microstructures of polished and etched surfaces at different magnifications. The tops of the ingots were cut along the diameter direction (transverse section) and the cross sections were subjected to a mechanical-chemical polishing and etched.

To reveal the microstructure of Ti specimens, a chemical etching with two reagents was used: reagent 1 (Kroll's reagent), prepared by $2 \mathrm{~mL} \mathrm{HF}, 3 \mathrm{~mL} \mathrm{HNO}_{3}$ and $100 \mathrm{~mL}$ distilled water and reagent 2-a solution composed of $20 \mathrm{~mL} \mathrm{HF}, 20 \mathrm{~mL} \mathrm{HNO}_{3}$ and $60 \mathrm{~mL}$ distilled water. The etching time was $80 \mathrm{~s}$ or $40 \mathrm{~s}$, respectively. Light microscopy was used to observe the microstructure after electron beam processing and this was related to the hardness by using the Brinell hardness test. The microstructures of the ingot cross section were characterized by a stereo microscope Leica M80 (Leica Microsystems $\mathrm{GmbH}$, Germany) and a light microscope Leica DM2500 (Leica Microsystems GmbH, Germany) with a digital camera Leica EC3 (Leica Microsystems GmbH, Germany). The Leica LAS software (Leica Microsystems $\mathrm{GmbH}$, Germany) was used for image processing.

Brinell hardness was tested for the Ti ingots manufactured at different melting powers $(2.5 \mathrm{~kW}$, $3.5 \mathrm{~kW}$ and $5.5 \mathrm{~kW}$ ). A hardened steel ball with a diameter of $2.5 \mathrm{~mm}$ (an indenter) with a maximum load of $62.5 \mathrm{~kg}$ was used. Three indentations were made in each sample to obtain an average value and a standard deviation.

A series of experiments were performed and using emission spectral analysis (spectrograph PGS-2, Carl Zeiss, Germany) the chemical composition variation of the materials before and after electron beam processing was defined. The composition was determined by averaging the results of five detected positions on the cross section (along the diameter direction), and the standard deviation of the chemical analysis concerning the investigated impurity components was $10 \mathrm{ppm}$.

The temperature was determined by an optical pyrometer QP-31 using special correction filters. The material losses were estimated using the mass of the initial materials and the ingots after melting that were weighted by electronic balance with a precision of $0.1 \mathrm{~g}$.

\section{Results and Discussion}

For each processing regime, the changes in the weight, chemical composition and structure of the ingots were controlled. The removal efficiency (degree of refining) was evaluated for each of the controlled impurities and the overall removal efficiency was calculated for each technological regime.

The evaluated values of the overall removal efficiency (removal efficiency of all the impurities of the sample) are presented in Table 1. It is seen that the increase of the electron beam power $\left(P_{b}\right)$ and also the increase of the melting time $(\tau)$ lead to an increase in the overall removal efficiency of the controlled impurities. Table 2 presents data for the material losses $\left(W_{\text {loss }}\right)$, which are mainly due to evaporation but also occur due to splashes.

Table 1. Overall removal efficiency $\eta$ at electron beam processing of titanium technogenic material.

\begin{tabular}{cccc}
\hline $\boldsymbol{P}_{\boldsymbol{b}} / \boldsymbol{\tau}$ & $\mathbf{1 5} \mathbf{~ m i n}$ & $\mathbf{2 5} \mathbf{~}$ in & $\mathbf{4 0 ~} \mathbf{~ i n}$ \\
\hline $\mathbf{2 . 5} \mathbf{~ k W}$ & $92.5 \%$ & $94.79 \%$ & $99.84 \%$ \\
$\mathbf{3 . 5} \mathbf{~} \mathbf{W}$ & $96.9 \%$ & $97.9 \%$ & $99.97 \%$ \\
$\mathbf{5 . 5} \mathbf{~ W W}$ & $98.71 \%$ & $99.8 \%$ & $99.975 \%$ \\
\hline
\end{tabular}

Table 2. Material losses $W_{\text {loss }}$ for $100 \mathrm{~g}$ melted Ti raw material.

\begin{tabular}{cccc}
\hline $\boldsymbol{P}_{\boldsymbol{b}} / \tau$ & $\mathbf{1 5} \mathbf{m i n}$ & $\mathbf{2 5} \mathbf{m i n}$ & $\mathbf{4 0 ~} \mathbf{m i n}$ \\
\hline $\mathbf{2 . 5} \mathbf{~ k W}$ & $1.7 \mathrm{~g}$ & $2.1 \mathrm{~g}$ & $3.8 \mathrm{~g}$ \\
$\mathbf{3 . 5} \mathbf{~ k W}$ & $2.6 \mathrm{~g}$ & $3.2 \mathrm{~g}$ & $4.4 \mathrm{~g}$ \\
$5.5 \mathrm{~kW}$ & $3.2 \mathrm{~g}$ & $5.4 \mathrm{~g}$ & $5.8 \mathrm{~g}$ \\
\hline
\end{tabular}


In Table 3, data about the chemical composition after melting under the investigated processing regimes is presented. The results obtained show that when the electron beam is operated at a lower power, the removal of $\mathrm{Fe}, \mathrm{Ir}, \mathrm{Cd}$ and $\mathrm{Cu}$ depends on the duration of the refining process and this dependence decreases as the melting power is raised. At a beam power of $5.5 \mathrm{~kW}$ the refining takes place during the first $15 \mathrm{~min}$ and afterwards the impurity concentration remains constant.

Table 3. Concentration of impurities at electron beam processing of titanium technogenic material.

\begin{tabular}{ccccccccccc}
\hline \multirow{2}{*}{ Sample No } & \multicolumn{1}{c}{ Process Parameters } & \multicolumn{7}{c}{$\boldsymbol{C}_{\boldsymbol{i}}(\mathbf{\%})$} \\
\cline { 2 - 12 } & $\mathbf{P}(\mathbf{k W})$ & $\boldsymbol{\tau}$ (min) & $\mathbf{S i}$ & $\mathbf{W}$ & $\mathbf{T a}$ & $\mathbf{A l}$ & $\mathbf{C u}$ & $\mathbf{C d}$ & $\mathbf{F e}$ & $\mathbf{I r}$ \\
\hline Ti-02 & 2.5 & 25 & 0.001 & 0.02 & 0.2 & 0.002 & 0.0003 & 0.3 & 0.3 & 0.01 \\
Ti-04 & 2.5 & 40 & 0.002 & 0.01 & 0 & 0.002 & 0.002 & 0.01 & 0 & 0 \\
Ti-03 & 3.5 & 25 & 0 & 0.02 & 0.2 & 0.003 & 0.0003 & 0.01 & 0.1 & 0.003 \\
Ti-06 & 3.5 & 40 & 0.002 & 0 & 0 & 0.003 & 0 & 0 & 0 & 0 \\
Ti-01 & 5.5 & 15 & 0.003 & 0.1 & 0.1 & 0.003 & 0.0001 & 0 & 0 & 0 \\
Ti-05 & 5.5 & 40 & 0.002 & 0 & 0 & 0.002 & 0 & 0 & 0 & 0 \\
Concentrations before EBM & 4.94 & 0.1 & 0.03 & 3.28 & 1.52 & 0.1 & 2.36 & 3.66 \\
\hline
\end{tabular}

Under the investigated melting regimes, the removal of $\mathrm{Al}, \mathrm{Si}$ and $\mathrm{W}$ is also effective. The removal occurs during the first $25 \mathrm{~min}$ and it is slightly dependent on the beam power (Table 3).

It is found that at a beam power of $5.5 \mathrm{~kW}$ for a melting time of $40 \mathrm{~min}$, the highest degree of refining of $99.975 \%$ is achieved with relatively low material losses (due to evaporation and splashes of metal), with $W_{\text {loss }}=5.8 \mathrm{~g}$ for $100 \mathrm{~g}$ of melted starting material, and with the obtained Ti having a purity of $99.996 \%$ (Tables 1-3). Under these processing conditions, the degree of refining of the controlled impurities such as $\mathrm{Ir}, \mathrm{Fe}, \mathrm{W}, \mathrm{Ta}, \mathrm{Cd}$ and $\mathrm{Cu}$ is $100 \%$.

This study investigated also the effects of the melting power and refining time on the microstructures of the Ti ingots. Macro-morphology of the initial (raw) Ti technogenic material (Ti gratings) is illustrated in Figure 2. It is seen that the material is not uniform. The chemical analysis of the raw material (before electron beam processing) showed a high content $(\approx 16 \%)$ of metal impurities ( $\mathrm{Ir}, \mathrm{Fe}, \mathrm{Al}, \mathrm{Cu}$, etc.) and the content of titanium is just $84.01 \%$ (Table 3).

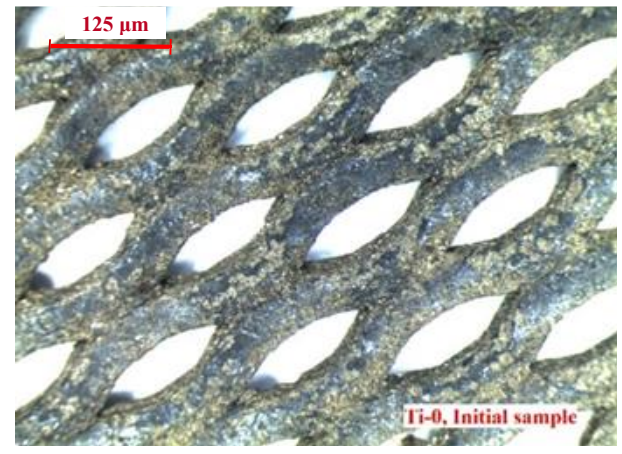

(a)

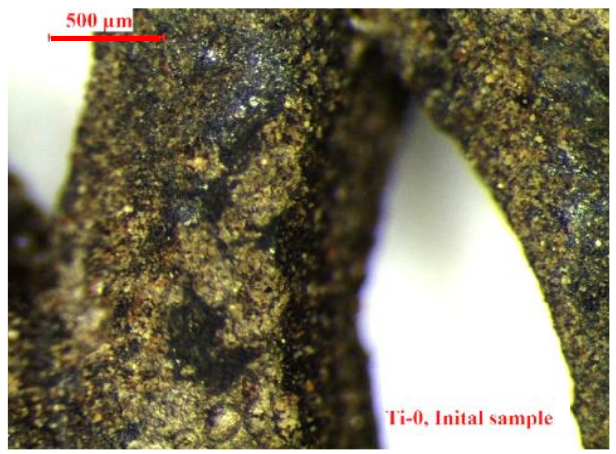

(b)

Figure 2. Ti material before electron beam processing: (a) 10×, (b) 40×.

In order to examine the effect of the beam power and melting time on the ingot morphology, the morphologies at the central part and near the edge part of ingot cross section were investigated and no significant differences were observed. The Ti sample two-phase macrostructures inspected by stereo microscope are presented in Figure 3. It can be seen that regardless of the different melting conditions - the beam power (and the temperature of overheating) and the isothermal retention-the macrostructure of the samples obtained does not differ significantly. By increasing the temperature (and the melting power) and extending the residence time, the ratio of the $\alpha$ phase (brighter) to $\beta$ phase (darker) increases. 


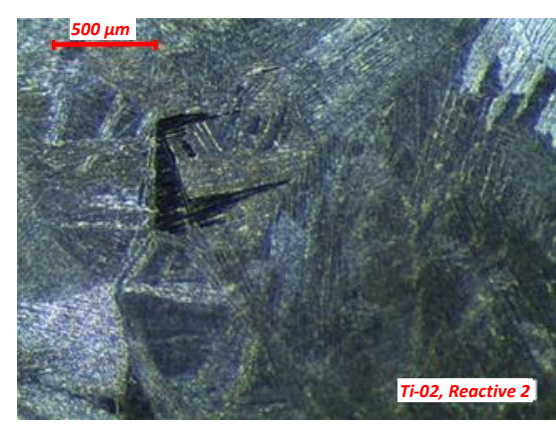

(a)

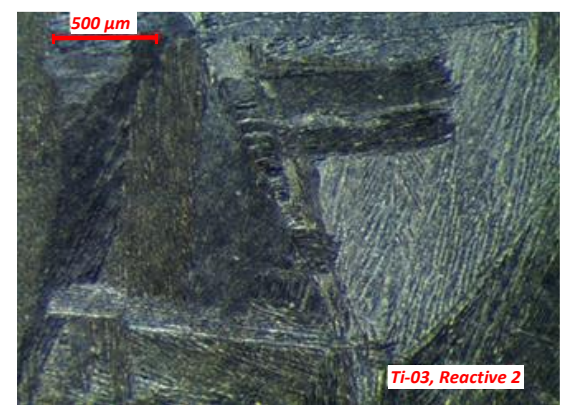

(c)

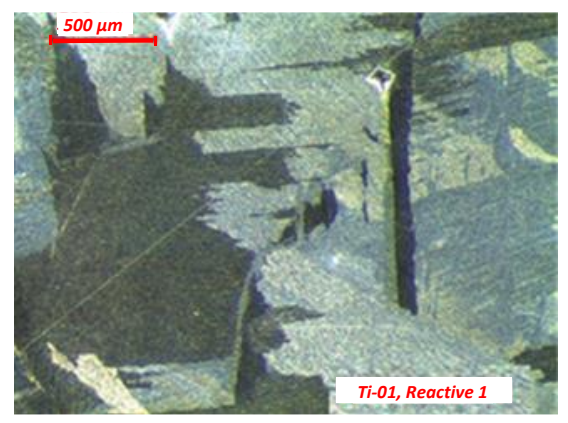

(e)

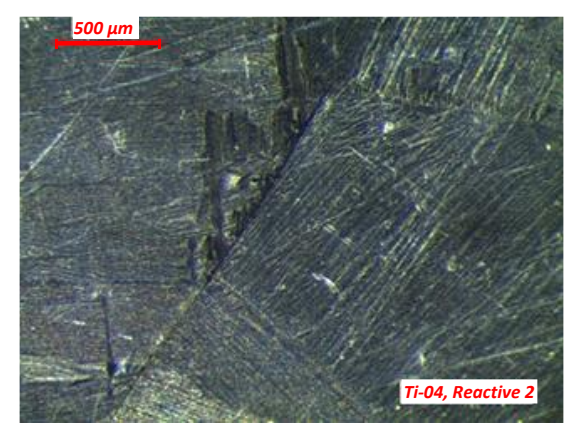

(b)

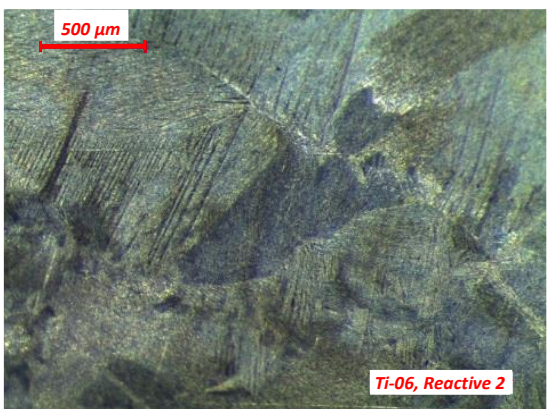

(d)

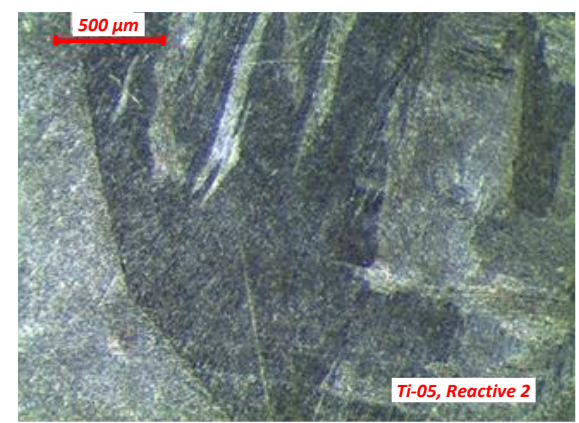

(f)

Figure 3. Macrostructures of the titanium ingots (40× magnification) manufactured at different melting conditions: (a) $P_{b}=2.5 \mathrm{~kW}, \tau=25 \mathrm{~min}$; (b) $P_{b}=2.5 \mathrm{~kW}, \tau=40 \mathrm{~min}$; (c) $P_{b}=3.5 \mathrm{~kW}, \tau=25 \mathrm{~min}$; (d) $P_{b}=3.5 \mathrm{~kW}$, $\tau=40 \mathrm{~min} ;(\mathbf{e}) P_{b}=5.5 \mathrm{~kW}, \tau=15 \mathrm{~min}$; and (f) $P_{b}=5.5 \mathrm{~kW}, \tau=40 \mathrm{~min}$.

The microstructure of the transformed $\beta \rightarrow \alpha$ phase may be seen more clearly at a higher magnification. Figure 4 shows the microstructures of the ingots obtained at different regimes and cooling to room temperature. They were observed through a light microscope at $400 \times$ magnification. An elongated/lamellar type structure [34] is observed on the cross section of the investigated metal samples. This type of structure is typical for Ti, which transforms from $\beta$ phase to $\alpha$ phase upon cooling. The formation of lamellar type structure takes place on the solid/liquid interface in the direction in which the heat is being led away. The $\beta$ to $\alpha$ phase transformation finished between $820-865^{\circ} \mathrm{C}$ for cooling rates between $50{ }^{\circ} \mathrm{C} / \mathrm{min}-10^{\circ} \mathrm{C} / \mathrm{min}$ [35].

The results (Tables 1 and 3 ) show that by raising the temperature and increasing the melting time, a higher degree of metal refining is obtained. This influences the obtained microstructure and the hardness of the metal. The Ti-02 and Ti-04 sample microstructures (Figure 4a,b) are composed of $\beta$ and $\alpha$ phases in approximately equal ratio, 1:1. These samples were obtained after electron beam processing of the Ti technogenic material at a melting power of $2.5 \mathrm{~kW}$ for different lengths of time- for 25 and $40 \mathrm{~min}$, respectively (Figure $4 \mathrm{a}, \mathrm{b}$ ). As a result of the extended electron beam irradiation, which leads to higher metal purity, the Ti-04 sample is characterized by better homogeneity than the microstructure of 
the Ti-02 (Figure 3a,b and Figure $4 a, b$ ). The different orientation of the lamellae is due to the difference in the rate of heat transfer from the micro volume of the smelt.

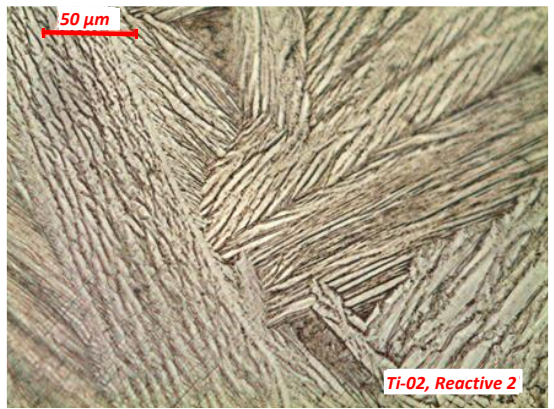

(a)

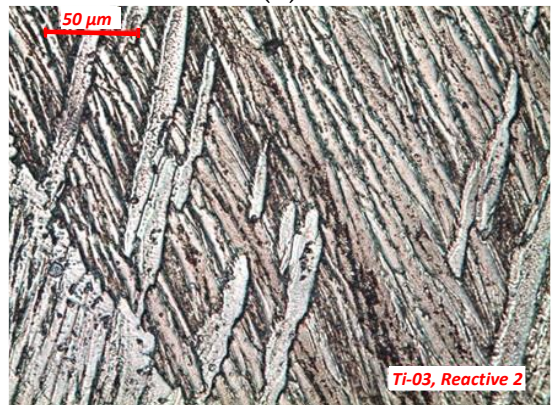

(c)

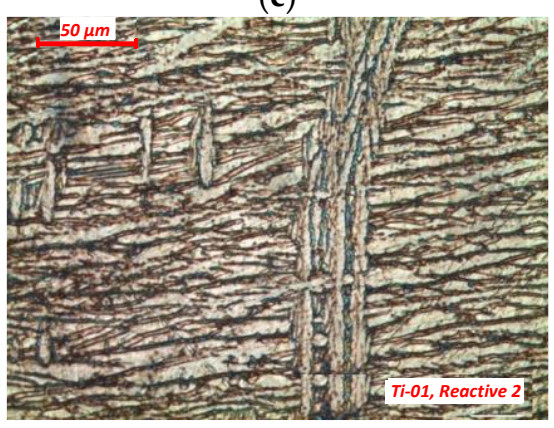

(e)

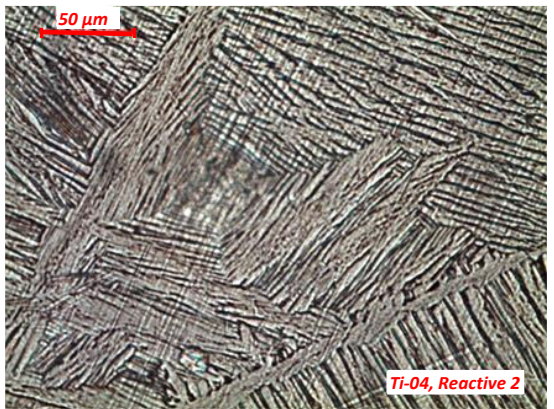

(b)

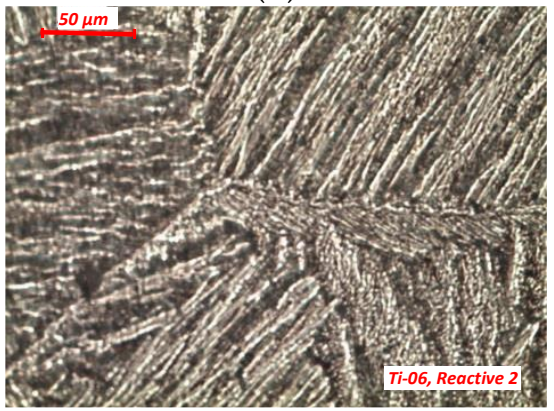

(d)

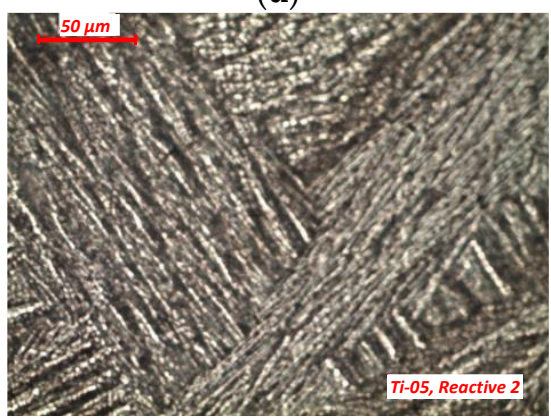

(f)

Figure 4. Optical micrographs (400× magnification) of the titanium ingots produced at different melting powers for different lengths of time: (a) $P_{b}=2.5 \mathrm{~kW}, \tau=25 \mathrm{~min}$; (b) $P_{b}=2.5 \mathrm{~kW}, \tau=40 \mathrm{~min}$; (c) $P_{b}=3.5 \mathrm{~kW}$, $\tau=25 \mathrm{~min} ;$ (d) $P_{b}=3.5 \mathrm{~kW}, \tau=40 \mathrm{~min} ;(\mathbf{e}) P_{b}=5.5 \mathrm{~kW}, \tau=15 \mathrm{~min}$; and (f) $P_{b}=5.5 \mathrm{~kW}, \tau=40 \mathrm{~min}$.

Based on the comparison between the microstructures of the Ti-03 and Ti-06 samples (Figure 4c,d), it is shown that the obtained lamellae are significantly larger and the $\alpha$ phase is predominantly observed. These ingots were obtained at a melting power of $3.5 \mathrm{~kW}$. By extending the refining time from $25 \mathrm{~min}$ (Ti-03) to $40 \mathrm{~min}$ (Ti-06), the metal purity increases to $\mathrm{Ti} 99.995 \%$ and the ingot morphology reaches that of pure titanium (Ti-06).

Experiments conducted at a beam power of $5.5 \mathrm{~kW}$ showed that a melting time of 15 min was not sufficient to completely remove the impurities and homogenize the smelt (Ti-01). The content of the impurities in the sample Ti-01 was $0.2016 \%$. The metal purity reached $\mathrm{Ti} 99.996 \%$ with the increase of the melting time to $40 \mathrm{~min}$ (Ti-05). The microstructures of the samples (Ti-01, Ti-05) obtained at these melting conditions are shown in Figure $4 \mathrm{e}, \mathrm{f}$. Large light lamellae formed by $\alpha$ phase can be seen on the microstructure of the sample Ti-01. They are arranged in an almost parallel manner and surrounded by $\beta$ phase. The microstructure of the sample Ti-05 is a typical Ti structure obtained by slow cooling.

The effects of the melting parameters on the microstructures of ingots (two times re-melted) fabricated via electron beam melting technology were investigated in a $\beta$-type Ti-Mo binary alloy and it was shown that the microstructures consisted of columnar grains at their top sections and they 
were similar at different melting powers (from $10.5 \mathrm{~kW}$ to $15.0 \mathrm{~kW}$ ) for a melting time ranging from $10 \mathrm{~min}$ to $40 \mathrm{~min}$ [29]. The microstructures of Ti-6Al-4V resulting from layered manufacturing using the electron beam process were predominantly characterized by acicular (basket-weave) $\alpha$ for solid structures [36-38] or acicular (basket-weave) $\alpha$ and martensite $\alpha^{\prime}$ for mesh and foam structures [37] or at the top of the sample [38]. Slow cooling rates favor the formation of similarly aligned $\alpha$ platelets in colonies, together with prior $\beta$ grain boundary $\alpha$. Faster cooling rates and higher $\beta$ stabilizing contents favor a more basket-weave type of structure [35].

The average Brinell hardness $\left(\mathrm{HB}_{\mathrm{av}}\right)$ and standard deviations measured are summarized in Table 4 . The results obtained show that the hardness of the titanium samples produced is influenced by melting time rather than by melting power. The average hardness of additive manufactured Ti-6Al-4V blocks decreases due to coarse $\alpha$-colonies, no (or much less) martensite and no (or much less) dislocations [39]. From Table 4 it can be seen that the hardness of Ti ingots decreases with an increase in melting time that leads to a softer and less heterogeneous material, i.e., an efficient refining of the impurities and their uniform distribution in the structure (the content of $\mathrm{Fe}, \mathrm{Si}, \mathrm{Al}, \mathrm{Cu}$ and $\mathrm{Ir}$ greatly decreases).

Table 4. Average hardness and standard deviation measured at titanium samples produced at different melting conditions.

\begin{tabular}{|c|c|c|c|c|}
\hline \multirow{2}{*}{ Sample № } & \multicolumn{2}{|c|}{ Process Parameters } & \multirow{2}{*}{$\mathrm{HB}_{\mathrm{av}}\left(\mathrm{kg} / \mathrm{mm}^{2}\right)$} & \multirow{2}{*}{ Standard Deviation } \\
\hline & $P(\mathrm{~kW})$ & $\tau(\min )$ & & \\
\hline Ti-02 & 2.5 & 25 & 282 & 28 \\
\hline Ti-04 & 2.5 & 40 & 161 & 23 \\
\hline Ti-03 & 3.5 & 25 & 292 & 25 \\
\hline Ti-06 & 3.5 & 40 & 100 & 7 \\
\hline Ti-01 & 5.5 & 15 & 205 & 17 \\
\hline Ti-05 & 5.5 & 40 & 120 & 11 \\
\hline \multicolumn{3}{|c|}{ before electron beam melting } & 127 & 10 \\
\hline
\end{tabular}

\section{Conclusions}

The effect of the electron beam method on the processing of titanium technogenic material under different melting conditions was examined in the present work. The influence of the melting power and melting time on the composition variation, microstructures of the ingots, hardness and degree of refining of titanium was studied in order to increase the process efficiency. It was found that melting time is an important factor for achieving a higher degree of metal refining and it affects the speed of crystallization during cooling. Hardness is influenced by melting time rather than by melting power. It is shown that with longer melting times, the purity of titanium increases, the hardness decreases, and the obtained ingots have an improved structure.

The maximal overall removal efficiency of $99.975 \%$ and the best purification of $\mathrm{Ti}(99.996 \%)$ were achieved at $5.5 \mathrm{~kW}$ melting power for a melting time of 40 min with relatively low material losses. It was also found, that under these melting conditions, the degree of refining of some impurities (such as iridium, iron, copper, tungsten, tantalum, and cadmium) was $100 \%$. The results show that the efficiency of electron beam processing of the titanium technogenic material with high level of impurities can be increased in order to improve the quality of the obtained high-purity metal and allow us to formulate requirements on the process conditions.

Author Contributions: K.V. and V.V. conceived and designed the experiments; V.V. performed the experiments; K.V., V.S and V.V. analyzed the data; all the authors contributed to the design of the study and interpretation of data; K.V., V.V. and V.S. wrote the manuscript.

Funding: This research received no external funding.

Acknowledgments: The work has been supported by the Bulgarian National Science Fund under contract DN17/9.

Conflicts of Interest: The authors declare no conflict of interest. 


\section{References}

1. Boyer, R.R. An overview on the use of titanium in the aerospace industry. Mater. Sci. Eng. A 1996, 213, 103-114. [CrossRef]

2. Lutjering, G.; Williams, J.C. Titanium, 2nd ed.; Springer: Berlin/Heidelberg, Germany, 2007; p. 442.

3. Banerjee, D.; Williams, J.C. Perspectives on Titanium Science and Technology. Acta Mater. 2013, 61, 844-879. [CrossRef]

4. Huo, D.; Liang, J.; Li, H.; Xie, S.; Yang, Y. Progress of Research and Application of Titanium Alloy. Foundry Technol. 2016, 10, 2065-2066.

5. Gao, L.; Huang, H.; Zhang, Y.; Zhang, H.; Shi, Z.; Jiang, Y.; Zhou, R. Numerical Modeling of EBCHM for Large-Scale $\mathrm{TC}_{4}$ Alloy Round Ingots. JOM 2018, 70, 2934-2942. [CrossRef]

6. Roh, K.-M.; Suh, C.-Y.; Oh, J.-M.; Kim, W.; Kwon, H.; Lim, J.-W. Comparison of deoxidation capability for preparation of low oxygen content powder from TiNi alloy scraps. Powder Technol. 2014, 253, 266-269. [CrossRef]

7. Zhao, Y.Q.; Ge, P. Current situation and development of new titanium alloys invented in China. J. Aeronaut. Mater. 2014, 34, 51-61.

8. An, H.; Liu, J.L.; Fan, L.Y. Quality control in smelting titanium ingots in vacuum arc-melting furnace. World Nonferr. Met. 2007, 8, 25-27.

9. Jin, H.X.; Wei, K.X.; Li, J.M.; Zhou, J.Y.; Peng, W.J. Research development of titanium alloy in aerospace industry. Chin. J. Nonferr. Met. 2015, 25, 280-292.

10. Mitchell, A. The electron beam melting and refining of titanium alloys. Mater. Sci. Eng. A 1999, 263, $217-223$. [CrossRef]

11. Tan, Y.; Shi, S. Progress in research and development of electron beam technology in metallurgy refining field. J. Mater. Eng. 2013, 8, 92-100.

12. Vassileva, V.; Vutova, K.; Mladenov, G. An Investigation on the Heat Transfer Influence on the Crystallisation Processes during the Electron Beam Melting and Casting of Metals. Vacuum 2001, 62, 197-202. [CrossRef]

13. Wang, X.; Liu, L.Q.; Li, X.M. Effect of crystallizer's three-dimension on the solid-liquid interface morphology of the large-scale Ti64 during EBCHM. Mater. Res. Express 2019. [CrossRef]

14. Liu, Q.L.; Li, X.M.; Jiang, Y.H. Microstructure evolution of large-scale titanium slab ingot based on CAFE method during EBCHM. J. Mater. Res. 2017, 32, 3175-3182. [CrossRef]

15. Park, H.K.; Ahn, Y.K.; Lee, B.S.; Jung, K.H.; Lee, C.W.; Kim, H.G. Refining effect of electron beam melting on additive manufacturing of pure titanium products. Mater. Lett. 2017, 187, 98-100. [CrossRef]

16. Dolimont, A.; Michotte, S.; Riviére-Lorphéver, E.; Ducobu, F.; De Formanoir, C.; Godet, S.; Filippi, E. Characterization of electron beam melting process (EBM): Capability approach. In Proceedings of the ASPE/Euspen 2016 Summer Topical Meeting: Dimensional Accuracy and Surface Finish in Additive Manufacturing, Raleigh, NC, USA, 27-30 July 2016; pp. 16-21.

17. Vassileva, V.; Mladenov, G.; Vutova, K.; Nikolov, T.; Georgieva, E. Oxygen removal during electron beam drip melting and refining. Vacuum 2005, 77, 429-436. [CrossRef]

18. You, Q.; Yuan, H.; You, X.; Li, J.; Zhao, L.; Shi, S.; Tan, Y. Segregation behavior of nickel-based superalloy after electron beam smelting. Vacuum 2017, 145, 116-122. [CrossRef]

19. Vutova, K.; Vassileva, V.; Naplatanova, M.; Tanaka, T. Refining effect of electron beam melting on recycling of nickel wastes. In Proceedings of the International Spring Seminar on Electronics Technology, Sofia, Bulgaria, 10-14 May 2017.

20. Liu, Q.L.; Li, X.M.; Jiang, Y.H. Research progress of electron beam cold hearth melting for titanium and titanium alloys. Hot Work. Technol. 2016, 45, 9-14.

21. Dolimont, A.; Michotte, S.; Rivière-Lorphèvre, E.; Ducobu, F.; Formanoir, C.D.; Godet, S.; Filippi, E. Characterisation of electron beam melting process on Ti6Al4V in order to guide finishing operation. Int. J. Rapid Manuf. 2015, 5, 320-338. [CrossRef]

22. Chen, X.; Li, X.; Jiang, Y.; Zhou, R. Effects of drawing velocity and casting temperature on solidification interface of the flat titanium ingot. Spec. Cast. Nonferr. Alloys 2016, 36, 412-415.

23. Liu, Q.; Jiang, Y.; Li, X. The effect of bulk nucleation parameters on the formation of macroscopic grain of the large-scale titanium slab ingot during EBCHM. Mater. Sci. Technol. 2018, 34, 1649-1656. [CrossRef] 
24. Oh, J.-M.; Lee, B.-K.; Choi, G.-S.; Kim, H.-S.; Lim, J.-W. Preparation of ultrahigh purity cylindrical tantalum ingot by electron beam drip melting without sintering process. Mater. Sci. Technol. 2013, 29, 542-546. [CrossRef]

25. Vutova, K.; Vassileva, V.; Koleva, E.; Georgieva, E.; Mladenov, G.; Mollov, D.; Kardjiev, M. Investigation of electron beam melting and refining of titanium and tantalum scrap. J. Mater. Process. Technol. 2010, 210, 1089-1094. [CrossRef]

26. Ma, Y.; Liu, Y.; Liu, W.; Long, L. Preparation procedure of high purity tungsten via electron beam side surface melting. Mater. Sci. Technol. 2014, 22, 30-35.

27. Vutova, K.; Vassileva, V.; Koleva, E.; Munirathnam, N.; Amalnerkar, DP.; Tanaka, T. Investigation of Tantalum Recycling by Electron Beam Melting. Metals 2016, 6, 287. [CrossRef]

28. Su, B.; Chen, D.M.; Wang, Z.H.; Ma, R.; Li, Y.F.; Xia, S.Q. Numerical Simulation of Electron Beam Melting Vanadium Alloys by Finite Element Method. Rare Met. Mater. Eng. 2019, 48, 711-715.

29. Yao, K.; Min, X.; Shi, S.; Tan, Y. Volatilization Behavior of $\beta$-Type Ti-Mo Alloy Manufactured by Electron Beam Melting. Metals 2018, 8, 206. [CrossRef]

30. Choi, S.H.; Jang, B.Y.; Lee, J.S.; Ahn, Y.S.; Yoon, W.Y.; Joo, J.H. Effects of electron beam patterns on melting and refining of silicon for photovoltaic applications. Renew. Energy 2013, 54, 40-45. [CrossRef]

31. Tan, Y.; Guo, X.L.; Shi, S.; Dong, W.; Jiang, D.C. Study on the removal process of phosphorus from silicon by electron beam melting. Vacuum 2013, 93, 65-70. [CrossRef]

32. You, X.G.; Tan, Y.; You, Q.F.; Shi, S.; Li, J.Y.; Ye, F.; Wei, X. Preparation of Inconel 740 superalloy by electron beam smelting. J. Alloys Compd. 2016, 676, 202-208. [CrossRef]

33. You, Q.; Yuan, H.; Zhaoa, L.; Lia, J.; Youa, X.; Shia, S.; Tana, Y.; Ding, X. Removal inclusions from nickel-based superalloy by induced directional solidification during electron beam smelting. Vacuum 2018, 156, 39-47. [CrossRef]

34. Voort, G.V. Preparation of Titanium and its Alloys. Tech. Notes 2015, 3, 1-5.

35. Pederson, R. Microstructure and Phase Transformation of Ti-6Al-4V. Licentiate Thesis, Lulea University of Technology, Lulea, Sweden, 2002.

36. Murr, L.E.; Quinones, S.A.; Gaytan, S.M.; Lopez, M.I.; Rodela, A.; Martinez, E.Y.; Hernandez, D.H.; Martinez, E.; Medina, F.; Wicker, R.B. Microstructure and mechanical behavior of Ti-6Al-4V produced by rapid-layer manufacturing, for biomedical applications. J. Mech. Behav. Biomed. Mater. 2009, 2, 21-32. [CrossRef] [PubMed]

37. Murr, L.E.; Amato, K.N.; Li, S.J.; Tian, Y.X.; Cheng, X.Y.; Gaytan, S.M.; Martinez, E.; Shindo, P.W.; Medina, F.; Wicker, R.B. Microstructure and mechanical properties of open-cellular biomaterials prototypes for total knee replacement implants fabricated by electron beam melting. J. Mech. Behav. Biomed. Mater. 2011, 4, 1396-1411. [CrossRef] [PubMed]

38. Al-Bermani, S.; Blackmore, M.; Zhang, W.; Todd, I. The Origin of Microstructural Diversity, Texture, and Mechanical Properties in Electron Beam Melted Ti6Al4V. Metall. Mater. Trans. A 2010, 41, 3422-3434. [CrossRef]

39. Brandl, E.; Schoberth, A.; Leyens, Ch. Morphology, microstructure, and hardness of titanium (Ti-6Al-4V) blocks deposited by wire-feed additive layer manufacturing (ALM). Mater. Sci. Eng. A 2012, 532, 295-307. [CrossRef]

(C) 2019 by the authors. Licensee MDPI, Basel, Switzerland. This article is an open access article distributed under the terms and conditions of the Creative Commons Attribution (CC BY) license (http://creativecommons.org/licenses/by/4.0/). 